\title{
Bleeding during pregnancy as a reason for interventions by emergency medical services teams in Poland
}

\author{
Ewa Rzońca ${ }^{1, A, C-F \oplus}$, Agnieszka Bień2,D,F ${ }^{\oplus}$, Joanna Gotlib ${ }^{1, F} \oplus$, Robert Gałązkowski ${ }^{1, B, E-F \oplus}$ \\ ${ }^{1}$ Medical University, Warsaw, Poland \\ ${ }^{2}$ Medical University, Lublin, Poland \\ A - Research concept and design, B - Collection and/or assembly of data, C - Data analysis and interpretation, \\ $D$ - Writing the article, E-Critical revision of the article, F-Final approval of the article
}

Rzońca E, Bień A, Gotlib J, Gałązkowski R. Bleeding during pregnancy as a reason for interventions by emergency medical services teams in Poland. Ann Agric Environ Med. 2022; 29(1): 110-114. doi: 10.26444/aaem/138158

\begin{abstract}
Introduction and objective. Vaginal bleeding during pregnancy is associated with risks to the health and life of the woman and/or the foetus. Moreover, it is usually unanticipated, which requires on-site care to be provided to the woman. Such care is handled by emergency medical services (EMS) teams until specialist obstetric care can be provided. The purpose of study was to analyze the characteristics of EMS team responses to calls regarding pregnant women with vaginal bleeding, considering the location of call: urban vs. rural area.

Materials and method. The study was based on a retrospective analysis of 5,487 EMS team interventions due to vaginal bleeding in pregnant women in Poland. The data analyzed included the period January 2018-December 2019, obtained from the National Monitoring Centre of Emergency Medical Services.

Results. The teams were more commonly dispatched to pregnant women in rural areas, who were more likely to be older and in the course of a second ( $27.52 \%$ vs. $26.88 \%$ ) or subsequent pregnancy $(34.00 \%$ vs. $27.49 \%)$, to have had one ( $28.22 \%$ vs. $26.75 \%)$ or more previous births ( $28.87 \%$ vs. $22.87 \%$ ), and to have antepartum bleeding ( $23.91 \%$ vs. $20.36 \%)$ than those from urban areas. The mean time between receipt of the call and patient hand-over at the hospital by the EMS team was longer in rural areas (50.00 vs. 37.23 minutes).

Conclusions. EMS teams responding to calls from rural areas regarding pregnant women with vaginal bleeding were most commonly dispatched in the summer, and the mean time between the receipt of the call and patient hand-over at the hospital was longer than in the calls from urban areas. Compared to patients calling from urban areas, those from rural areas were also more likely to be pregnant for the second or subsequent time, to have antepartum bleeding, and to have given birth before.
\end{abstract}

\section{Key words}

pregnant women, emergency medical service, vaginal bleeding

\section{INTRODUCTION}

Pregnancy is a natural condition associated with a number of anatomical and physiological changes resulting from the adaptation of a woman's body to the needs of a developing foetus and preparation for delivery. Even in the normal course of pregnancy, signs and symptoms of obstetric complications may occur $[1,2]$. Alarming symptoms during the pregnancy include vaginal bleeding, abdominal pain, swelling, headaches, fever, or marked changes in foetal movement. These symptoms may be associated with a risk to the health and life of the woman and/or foetus, and are usually unexpected [2-5].

Vaginal bleeding is an alarming symptom that may occur at any time during pregnancy [2-5]. In early pregnancy, bleeding occurs in approx. $25 \%$ of women [6] and is most commonly associated with miscarriage or ectopic pregnancy [3-10]. Later in the pregnancy, bleeding may mark the beginning of a preterm labour, and may result in a haemorrhage threatening the health of the woman and

Address for correspondence: Ewa Rzońca, Medical University, Warsaw, Poland E-mail: erzonca@wum.edu.pl

Received: 14.04.2021; accepted: 22.05.2021; first published: 28.05.2021 the foetus. In the second and third trimester, severe or lifethreatening conditions associated with vaginal bleeding include placental abruption and placenta previa [3, 11-16].

Risks to the health or life of the pregnant woman may occur at any time during pregnancy $[3,12]$. The Polish Emergency Medical Services (EMS) have been established to provide care to patients with severe or life-threatening emergencies. The Polish EMS system consists of hospital emergency departments and emergency medical services teams, including air medical services teams. Emergency medical services teams and air medical services teams are units of the EMS system responsible for responding to emergencies and performing medical emergency procedures on site and during transport to hospital. EMS teams may include physicians, emergency medical technicians, and nurses, and are classified as non-physician-staffed and physician-staffed [17].

The present study was motivated by the potential risks to pregnant women's health or life associated with vaginal bleeding, necessitating the provision of care on site by an EMS team $[2,3,5,8,11,12,16]$. 


\section{OBJECTIVE}

The aim of the study was to analyze the characteristics of emergency medical services (EMS) team responses to calls regarding pregnant women with vaginal bleeding, considering the location of call: urban vs. rural area.

\section{MATERIALS AND METHOD}

The study was based on a retrospective analysis of EMS team interventions due to vaginal bleeding in pregnant women in Poland, based on data from the Emergency Medical Services' command support system for the period January 2018-December 2019, prepared by the National Monitoring Centre of Emergency Medical Services. The centre's Information and Technology Communication (ICT) system is used to register calls and information from emergency numbers, dispatch EMS teams, register medical events, and locate each event [18]. Data obtained from its database included emergency medical procedure records and EMS team dispatch records. The documentation was analyzed to obtain the following information: date and location of call, details of the pregnant patient, main diagnoses based on the International Statistical Classification of Diseases and Related Health Problems (ICD-10), patient clinical parameters, emergency medical procedures performed, and other characteristics of the intervention. The study was approved by the Polish Ministry of Health, which also provided the data for analysis. The study protocol was submitted to the Bioethics Committee at the Medical University of Warsaw, which confirmed that this study did not require consent due to its retrospective nature (AKBE/17/2021).

The study included all cases of vaginal bleeding in pregnant women classified by the EMS team under ICD-10 codes O20 - haemorrhage in early pregnancy, O44 - placenta previa, O45 - premature separation of placenta (abruptio placentae), or $\mathrm{O} 46$ - antepartum haemorrhage, not classified elsewhere. Exclusion criteria were: refusal of medical assistance, cancellation of call, absence of the patient on site. Of the 6,396,387 EMS team interventions in Poland in the period analyzed, 5,487 EMS team interventions regarding pregnant women with vaginal bleeding were selected for further analysis, based on the established criteria and after accounting for missing data in the medical records.

The data obtained from the documentation analysis were analyzed statistically using the STATISTICA software, version 13.2 (Tibco Software Inc., Palo Alto, CA, USA). Qualitative data were described using numbers (n) and percentages (\%), while quantitative data were reported using means (M) and standard deviations (SD). Distribution normality for quantitative variables was tested using the Kolmogorov-Smirnov test and the Lilliefors test. Statistically significant differences between qualitative variables were tested using the $\mathrm{Chi}^{2}$ test, and differences between two independent groups were tested using the non-parametric Mann-Whitney U-test. Correlations and differences at $\mathrm{p}<0.05$ were considered statistically significant.

\section{RESULTS}

Table 1 shows the characteristics of the pregnant patients, and an analysis of relationships between selected variables regarding the patients and their obstetric history, and location of call (urban/rural area). The mean age of the women studied was 29.61 years, and the most numerous age range was 30-34 years $(28.45 \%)$. Most patients were pregnant for the first time (43.21\%), in their first trimester $(66.16 \%)$ - at 15.12 weeks, on average, and had nopreviously given birth (47.85\%) or miscarried (88.24\%). Early pregnancy bleeding was identified in most cases (78.44\%).

Pregnant women from rural areas who received assistance from EMS teams were older, on average (mean age 29.92 years), than patients from urban areas. Compared to patients with vaginal bleeding during pregnancy calling from urban areas, those from rural areas were also more likely to be pregnant for the second or subsequent time, in the second or third trimester, and at a later gestational week, to have antepartum bleeding, and to have given birth before. All these associations were statistically significant $(\mathrm{p}<0.05)$ (Tab. 1).

Overall, EMS teams were more often dispatched to pregnant women with vaginal bleeding in the summer (26.88\%), between 07:00-18:59 (53.98\%), with urgency code

Table 1. Characteristics of patients and their obstetric history, and analysis of relationships between selected variables and location of call

\begin{tabular}{|c|c|c|c|c|}
\hline \multirow{2}{*}{ Variables } & \multirow{2}{*}{ Total } & \multicolumn{2}{|c|}{ Location of call } & \multirow{2}{*}{$\mathrm{p}$-value } \\
\hline & & Urban area & Rural area & \\
\hline \multicolumn{5}{|l|}{ Age $-\mathrm{n}(\%)$} \\
\hline $15-19$ years & $358(6.52)$ & $140(6.60)$ & $118(6.37)$ & \multirow{6}{*}{0.1575} \\
\hline $20-24$ years & $915(16.68)$ & $613(16.87)$ & $302(16.30)$ & \\
\hline $25-29$ years & $1,343(24.48)$ & $910(25.04)$ & $433(23.37)$ & \\
\hline $30-34$ years & $1,561(28.45)$ & $1,044(28.93)$ & $517(27.90)$ & \\
\hline $35-39$ years & $966(17.61)$ & $614(16.90)$ & $352(19.00)$ & \\
\hline 40 and older & $344(6.27)$ & $213(5.86)$ & $131(7.07)$ & \\
\hline Mean age $-M(S D)$ & $29.61(6.42)$ & $29.45(6.35)$ & $29.92(6.55)$ & 0.0104 \\
\hline \multicolumn{5}{|l|}{ Pregnancy - n (\%) } \\
\hline 1 & $2371(43.21)$ & $1658(45.62)$ & $713(38.48)$ & \multirow{3}{*}{0.0000} \\
\hline 2 & $1,487(27.10)$ & $977(26.88)$ & $510(27.52)$ & \\
\hline 3 or more & $1,629(29.69)$ & 999 (27.49) & $630(34.00)$ & \\
\hline \multicolumn{5}{|l|}{ Trimester - n (\%) } \\
\hline first trimester & $3,630(66.16)$ & $2,454(67.53)$ & $1,176(63.46)$ & \multirow{3}{*}{0.0064} \\
\hline second trimester & $832(15.16)$ & $539(14.83)$ & $293(15.81)$ & \\
\hline third trimester & $1,025(18.68)$ & $641(17.64)$ & $384(20.72)$ & \\
\hline Gestational week - M (SD) & $15.12(10.11)$ & $14.84(9.97)$ & $15.69(10.34)$ & 0.0036 \\
\hline \multicolumn{5}{|l|}{ Previous labur - n (\%) } \\
\hline $0 /$ no & $2,626(47.85)$ & $1831(50.39)$ & $795(42.90)$ & \multirow{3}{*}{0.0000} \\
\hline 1 & $1,495(27.25)$ & $972(26.75)$ & $523(28.22)$ & \\
\hline 2 or more & $1,366(24.90)$ & $831(22.87)$ & $535(28.87)$ & \\
\hline \multicolumn{5}{|l|}{ History of miscarriage - $\mathrm{n}(\%)$} \\
\hline Yes & $645(11.76)$ & $424(11.67)$ & $221(11.93)$ & \multirow{2}{*}{0.7782} \\
\hline No & $4,842(88.24)$ & $3,210(88.33)$ & $1,632(88.07)$ & \\
\hline \multicolumn{5}{|l|}{ Bleeding - n (\%) } \\
\hline in early pregnancy & $4,304(78.44)$ & $2,894(79.64)$ & $1,410(76.09)$ & \multirow{2}{*}{0.0025} \\
\hline antepartum & $1,183(21.56)$ & $740(20.36)$ & $443(23.91)$ & \\
\hline
\end{tabular}


2 (58.06\%). Most were two-person (60.31\%), non-physicianstaffed teams (60.31\%). The mean duration of intervention, i.e. time between receipt of the call and hand-over of the pregnant patient at the hospital, was 41.56 minutes. An emergency call regarding vaginal bleeding during pregnancy was most often made by the pregnant patient herself (26.43\%), but in more than half of the cases studied, the caller was unidentified (53.91\%) (Tab. 2).

As for calls from rural areas, EMS teams were more often dispatched in the summer, between 19.00-06.59, with urgency code 1 ; most teams were composed of two people; and most calls were made by a family member of the patient. The mean time between receipt of the call and patient hand-over at the hospital by the EMS team was longer in rural areas than in urban areas (50.00 vs. 37.23 min.). The above associations were statistically significant $(\mathrm{p}<0.05)$, although no statistically significant correlation was found between EMS team type and location of call (p>0.05) (Tab. 2).

Emergency medical procedures most commonly performed by EMS team members for pregnant patients with vaginal bleeding were blood pressure measurement (92.98\%) and pulse oximetry (91.53\%). In the studied cases of calls to pregnant patients with vaginal bleeding, EMS call location was significantly correlated with the procedures performed, including blood pressure measurement, physical examination, vital parameter monitoring, intravenous cannulation, and

Table 2. Characteristics of interventions and analysis of relationships between selected variables and location of call

\begin{tabular}{|c|c|c|c|c|}
\hline \multirow{2}{*}{ Variables } & \multirow{2}{*}{ Total } & \multicolumn{2}{|c|}{ Location of call } & \multirow{2}{*}{ p-value } \\
\hline & & Urban area & Rural area & \\
\hline \multicolumn{5}{|l|}{ Time of year - n (\%) } \\
\hline Spring & $1,340(24.42)$ & $881(24.24)$ & $459(24.77)$ & \multirow{4}{*}{0.0023} \\
\hline Summer & $1,475(26.88)$ & $928(25.54)$ & $547(29.52)$ & \\
\hline Autumn & $1,324(24.13)$ & $887(24.41)$ & $437(23.58)$ & \\
\hline Winter & $1,348(24.57)$ & $938(25.81)$ & $410(22.13)$ & \\
\hline \multicolumn{5}{|l|}{ Time of call - n (\%) } \\
\hline 07:00-18:59 & $2,962(53.98)$ & $2,008(55.26)$ & $954(51.48)$ & \multirow{2}{*}{0.0080} \\
\hline 19:00-06:59 & $2,525(46.02)$ & $1,626(44.74)$ & $899(48.52)$ & \\
\hline \multicolumn{5}{|l|}{ Urgency code - n (\%) } \\
\hline code 1 & 2,301 (41.94) & $1,400(38.63)$ & $901(48.62)$ & \multirow{2}{*}{0.0000} \\
\hline code 2 & $3,186(58.06)$ & $2,234(61.47)$ & $952(51.38)$ & \\
\hline \multicolumn{5}{|l|}{ EMS team type - n (\%) } \\
\hline non-physician-staffed & $4,215(76.82)$ & $2,785(76.64)$ & ,430 (77.17) & \multirow{2}{*}{0.6571} \\
\hline physician-staffed & $1,272(23.18)$ & $849(23.36)$ & $423(22.83)$ & \\
\hline \multicolumn{5}{|c|}{ EMS team composition — n (\%) } \\
\hline two-person & $3,309(60.31)$ & $2,153(59.25)$ & $1,156(62.39)$ & \multirow{2}{*}{0.0246} \\
\hline three-person & 2,178 (39.69) & $1,481(40.75)$ & $697(37.61)$ & \\
\hline $\begin{array}{l}\text { Time between } \\
\text { the receipt of call and } \\
\text { patient hand-off at the } \\
\text { hospital - M (SD) }\end{array}$ & $41.56(17.73)$ & $37.23(16.24)$ & $50.00(17.47)$ & 0.0000 \\
\hline \multicolumn{5}{|l|}{ Caller - n (\%) } \\
\hline pregnant patient & $1,450(26.43)$ & 1,017 (27.99) & $433(23.37)$ & \multirow{4}{*}{0.0000} \\
\hline family member & $664(12.10)$ & $427(11.75)$ & $237(12.79)$ & \\
\hline other & $415(7.56)$ & $307(8.45)$ & $108(5.83)$ & \\
\hline unidentified & $2,958(53.91)$ & $1,883(51.82)$ & $1,075(58.01)$ & \\
\hline
\end{tabular}

blood glucose measurement, as well as with systolic blood pressure values $(\mathrm{p}<0.05)$. No significant relationship was found between selected physical examination findings or use of pulse oximetry and location of call ( $p>0.05$ ) (Tab. 3).

\section{DISCUSSION}

Vaginal bleeding during pregnancy is associated with risks to the health and life of the woman and/or the foetus. Moreover, it is usually unanticipated, and care must be provided on site by the EMS team until the patient is safely transferred to specialist obstetric care $[2,3,5,8,11,12,13,16]$. This aspect motivated the present study, the aim of which was to analyze the characteristics of emergency medical services (EMS) team responses to calls regarding pregnant women with vaginal bleeding, considering the location of call: urban vs. rural area. Importantly, vaginal bleeding in the first trimester is among the most common complications of pregnancy, occurring in $15-25 \%$ of cases, and results in miscarriage in approximately half of them. In turn, patients who are still pregnant after an episode of bleeding are at a higher risk of complications at later stages of pregnancy, including preterm birth or premature separation of placenta [16, 19-22].

Table 3. Characteristics of selected emergency medical procedures performed by EMS teams and selected physical examination findings, and analysis of relationships between these variables and location of call

\begin{tabular}{lll}
\hline \multirow{2}{*}{ Variables } & Total & \multicolumn{2}{c}{ Location of call } \\
\cline { 3 - 3 } & Urban area Rural area & R-value \\
\hline
\end{tabular}

Most common emergency procedures $-\mathrm{n}(\%)$

\begin{tabular}{|c|c|c|c|c|}
\hline $\begin{array}{l}\text { Blood pressure } \\
\text { measurement }\end{array}$ & $5,102(92.98)$ & $3,332(91.69)$ & $1,770(95.52)$ & 0.0000 \\
\hline Pulse oximetry & $5,022(91.53)$ & $3,307(91.00)$ & $1,715(92.55)$ & 0.0488 \\
\hline Physical examination & $3,988(72.68)$ & $2,694(74.13)$ & $1,294(69.83)$ & 0.0007 \\
\hline Monitoring & $3,072(55.99)$ & $1,976(54.38)$ & $1,096(59.15)$ & 0.0008 \\
\hline Intravenous cannulation & $2,071(37.74)$ & $1,241(34.15)$ & $830(44.79)$ & 0.0000 \\
\hline $\begin{array}{l}\text { Blood glucose } \\
\text { measurement }\end{array}$ & $1,441(26.26)$ & $8,72(24.00)$ & $569(30.71)$ & 0.0000 \\
\hline \multicolumn{5}{|c|}{ Selected physical examination findings - n (\%) } \\
\hline Abdominal tenderness & $1,282(23.36)$ & $836(23.00)$ & $4,46(24.07)$ & 0.3783 \\
\hline $\begin{array}{l}\text { Abnormal respiratory } \\
\text { sounds }\end{array}$ & $1,006(18.33)$ & $683(18.79)$ & $3,23(17.43)$ & 0.2170 \\
\hline Pallor & $501(9.13)$ & $314(8.64)$ & $187(10.09)$ & 0.0776 \\
\hline Fainting & $121(2.21)$ & $79(2.17)$ & $42(2.27)$ & 0.8250 \\
\hline Vomiting & $117(2.13)$ & $84(2.31)$ & $33(1.78)$ & 0.1982 \\
\hline $\mathrm{GCS}-\mathrm{M}(\mathrm{SD})$ & $14.99(0.15)$ & $14.99(0.15)$ & $14.99(0.15)$ & 0.8618 \\
\hline RTS - M (SD) & $11.97(0.23)$ & $11.97(0.24)$ & $11.97(0.23)$ & 0.9151 \\
\hline $\begin{array}{l}\text { Respiration rate - } \\
\text { breath/min M (SD) }\end{array}$ & $15.86(2.69)$ & $15.87(2.70)$ & $15.82(2.66)$ & 0.5371 \\
\hline Saturation - \% M (SD) & $98.00(1.27)$ & $97.99(1.32)$ & $98.02(1.18)$ & 0.7070 \\
\hline $\begin{array}{l}\text { Systolic blood pressure } \\
-\mathrm{mmHg} \mathrm{M}(\mathrm{SD})\end{array}$ & $\begin{array}{l}125.23 \\
(17.58)\end{array}$ & $\begin{array}{l}124.74 \\
(17.32)\end{array}$ & $\begin{array}{l}126.15 \\
(18.02)\end{array}$ & 0.0101 \\
\hline $\begin{array}{l}\text { Diastolic blood pressure } \\
-\mathrm{mmHg} \mathrm{M}(\mathrm{SD})\end{array}$ & $77.35(11.66)$ & $77.26(11.69)$ & $77.53(11.62)$ & 0.2704 \\
\hline $\begin{array}{l}\text { Heart rate - beat/min } \\
M(S D)\end{array}$ & 93.25 (16.47) & $93.41(16.73)$ & $92.94(15.96)$ & 0.4458 \\
\hline $\begin{array}{l}\text { Blood glucose }-\mathrm{mg} / \mathrm{dL} \\
\mathrm{M}(\mathrm{SD})\end{array}$ & $\begin{array}{l}106.97 \\
(24.96)\end{array}$ & $\begin{array}{l}105.91 \\
(23.40)\end{array}$ & $\begin{array}{l}108.59 \\
(27.12)\end{array}$ & 0.0521 \\
\hline
\end{tabular}

GCS - Glasgow Coma Scale; RTS - Revised Trauma Score 
Vaginal bleeding in early pregnancy is most commonly associated with miscarriage [3-10]. There are numerous risk factors for miscarriage, including advanced age, history of miscarriage, substance use, patient's abnormally low or high body weight, history of preterm birth, history of stillbirth, history of Caesarean section, and gestational diabetes in a previous pregnancy [23-27]. The findings of the current show that early pregnancy bleeding was identified in most of the cases studied.

Singh et al. (2018) studied the use of emergency medical services by pregnant women in two statesinf India. They found that approximately one in three of the women studied had a high-risk pregnancy or pregnancy complications [28]. Bills et al. (2018) published a study on decreases in the early neonatal mortality rate in India in the context of EMS use by pregnant women. Most newborns included in the analysis had been born to mothers living in rural areas. At the time of the first EMS call, most pregnant patients were at term. The most common reasons for the call were abdominal pain and spasm, followed by rupture of membranes, contractions, and vaginal bleeding [29]. Findings similar to those by Bills et al. (2018) [29] were reported by Singh et al. (2017) in their study on pregnant women transferred to healthcare centres by emergency medical services in five statinf India [30]. Another study on the characteristics of women using EMS in India due to pregnancy-related problems in the third trimester was performed by Strehlow et al. (2016). The authors found that women from rural areas were more likely to use EMS [31]. The current findings are consistent with those cited above, as in Poland EMS teams were also more commonly dispatched to pregnant women from rural areas who were pregnant for the second or subsequent time, in the second or third trimester, with antepartum bleeding, and who had previously given birth.

In the literature, multiple authors have focused on the specific characteristics of EMS interventions for different health problems and hazards, as emphasize, e.g. by Cantwell et al. (2016), Faramand et al. (2019), Ramgopal et al. (2019) and Javaudin et al. (2019) [32-35]. A similar analysis was performed in the current study. Rzońca et al. (2019) compared HEMS missions carried out in Poland and demonstrated that HEMS teams were dispatched most often in the period May-August [37]. Another study by Rzońca et al. (2019) included an analysis of HEMS missions in rural areas over an 8-year period, and found that most such HEMS missions in rural areas occurred in the summer [38]. The current study demonstrated that in cases of vaginal bleeding in pregnant patients from rural areas, EMS teams were more often dispatched in the summer, between 19:00-06:59, with urgency code 1 . Strehlow et al. (2016) demonstrated that the time between the call and transfer to hospital was longer in cases of pregnant patients from rural areas, compared to those from urban areas [31], which is also corroborated by the presented findings.

An interesting study on emergency response in cases of non-hospitalized patients at the University of Pennsylvania hospital in the USA was performed by Dechert et al. (2013). The authors found that the subjects, including outpatients, visitors, and hospital staff, were most commonly given oxygen and intravenous fluids [39]. Strehlow et al. (2016) also reported that EMS team members almost always measured the pregnant patients' heart rate and blood pressure, and placed them in the left lateral position [31]. Rzońca et al.
(2019) found that HEMS missions in rural areas more often involved mechanical ventilation, patient immobilization, intravenous cannulation, chest compressions, and endotracheal intubation [37]. In the current study, EMS interventions in rural areas for pregnant patients with vaginal bleeding most commonly included the following procedures: blood pressure measurement, monitoring of vital parameters, intravenous cannulation, and blood glucose measurement.

The presented study is the first Polish analysis of all calls registered by the National Monitoring Centre of Emergency Medical Services in 2018-2019, which constitutes its strength, as it has allowed for developing a credible characterization of EMS interventions in cases of women with bleeding during pregnancy. However, the presented study also has certain limitations. The analysis only included information contained in the EMS documentation, with no data on subsequent patient management, patient health, or obstetric outcome. These limitations do not, however, impair the quality of the study. Notably, the study addresses the important issue of differences between rural and urban areas in terms of the health problems experienced and care received (in this case, from EMS teams in Poland) by women during pregnancy. The findings indicate the need for more health promotion efforts focused on pregnant women. Further studies on the health problems of pregnant patients are warranted to provide a better understanding of the subject, and ensure that the best possible care is provided to these patients by EMS teams.

\section{CONCLUSIONS}

EMS teams are a key component in the pre-hospital care system, providing on-scene assistance to patients, including pregnant women, with various health emergencies. EMS teams were most commonly dispatched to pregnant patients with vaginal bleeding who were aged 30-34, pregnant for the first time, in the first trimester, with early pregnancy bleeding.

Location (urban vs. rural) differentiated EMS team calls to pregnant women with vaginal bleeding in terms of the woman's age, number of past pregnancies and births, trimester, gestational week, type of bleeding, time of the year, time of call, urgency code, EMS team composition, time between receipt of the call, and patient hand-over at the hospital, caller, and selected emergency medical procedures performed.

EMS teams in Poland responding to calls from rural areas regarding pregnant women with vaginal bleeding were most commonly dispatched in the summer, with urgency code 1 , and the mean time between receipt of the call and patient hand-over at the hospital was longer than in the case of calls from urban areas. Compared to patients with vaginal bleeding during pregnancy calling from urban areas, those from rural areas were also more likely to be pregnant for the second or subsequent time, in the second or third trimester, to have antepartum bleeding, and to have previously given birth.

\section{REFERENCES}

1. King TL, Davidson MR, Avery CD, et al. Anatomy and physiology of pregnancy: placental, fetal, and maternal adaptations. In: King TL, Brucker MC, Kriebs JM, Fahey JO, Gegor CL, Varney H, editors. Varney's Midwifery. 5th ed. Jones \& Bartlett Learning; 2015. p. 599-627. 
2. Rashad WA, Essa RM. Women's Awareness of Danger Signs of Obstetrics Complications. J Am Sci. 2010; 6(10): 1299-1306. doi:10.7537/ marsjas061010.149

3. Nowacka E, Światek-Zdzienicka M, Jarzębski R. Stany zagrożenia życia w położnictwie. Anest Inten Terap. 2004; 36: 286-292.

4. Mwilike B, Nalwadda G, Kagawa M, et al. Knowledge of danger signs during pregnancy and subsequent healthcare seeking actions among women in Urban Tanzania: a cross-sectional study. BMC Pregnancy Childbirth. 2018; 18(1): 4. doi: 10.1186/s12884-017-1628-6

5. Gregory DS, Wu V, Tuladhar P. The Pregnant Patient: Managing Common Acute Medical Problems. Am Fam Physician. 2018; 98(9) 595-602.

6. Hendriks E, MacNaughton H, MacKenzie MC. First Trimester Bleeding: Evaluation and Management. Am Fam Physician. 2019; 99(3): 166-174.

7. Hasan R, Baird DD, Herring AH, et al. Patterns and predictors of vaginal bleeding in the first trimester of pregnancy. Ann Epidemiol. 2010; 20(7): 524-31. doi: 10.1016/j.annepidem.2010.02.006

8. Breeze C. Early pregnancy bleeding. Aust Fam Physician. 2016; 45(5): 283-6.

9. Knez J, Day A, Jurkovic D. Ultrasound imaging in the management of bleeding and pain in early pregnancy. Best Pract Res Clin Obstet Gynaecol. 2014; 28(5): 621-36. doi: 10.1016/j.bpobgyn.2014.04.003

10. Ticconi C, Pietropolli A, Specchia M, et al. Pregnancy-Related Complications in Women with Recurrent Pregnancy Loss: A Prospective Cohort Study. J Clin Med. 2020; 9(9): 2833. doi: 10.3390/jcm9092833

11. Yang J, Savitz DA, Dole N, et al. Predictors of vaginal bleeding during the first two trimesters of pregnancy. Paediatr Perinat Epidemiol. 2005; 19(4): 276-83. doi: 10.1111/j.1365-3016.2005.00655.x

12. Young JS, White LM. Vaginal Bleeding in Late Pregnancy. Emerg Med Clin North Am. 2019; 37(2): 251-264. doi: 10.1016/j.emc.2019.01.006

13. Sakornbut E, Leeman L, Fontaine P. Late pregnancy bleeding. Am Fam Physician. 2007; 75(8): 1199-206.

14. Li Y, Tian Y, Liu N, et al. Analysis of 62 placental abruption cases: Risk factors and clinical outcomes. Taiwan J Obstet Gynecol. 2019; 58(2): 223-226. doi: 10.1016/j.tjog.2019.01.010

15. Downes KL, Grantz KL, Shenassa ED. Maternal, Labor, Delivery, and Perinatal Outcomes Associated with Placental Abruption: A Systematic Review. Am J Perinatol. 2017; 34(10): 935-957. doi: 10.1055/s-00371599149

16. Raj SS, Manthri S, Sahoo PK. Emergency referral transport for maternal complication: lessons from the community based maternal death audits in Unnao district, Uttar Pradesh, India. Int J Health Policy Manag. 2015; 4(2): 99-106. doi: 10.15171/ijhpm.2015.14

17. Ustawa z dnia 8 września 2006 r. o Państwowym Ratownictwie Medycznym (Dz.U. 2019 poz. 993).

18. System Wspomagania Dowodzenia Państwowego Ratownictwa Medycznego (SWD PRM) https://www.gov.pl/web/zdrowie/systemwspomagania-dowodzenia-panstwowego-ratownictwa-medycznegoswd-prm- (access: 12.02.2021)

19. Ananth CV, Oyelese Y, Prasad V, et al. Evidence of placental abruption as a chronic process: associations with vaginal bleeding early in pregnancy and placental lesions. Eur J Obstet Gynecol Reprod Biol. 2006; 128(1-2): 15-21. doi: 10.1016/j.ejogrb.2006.01.016

20. Hossain R, Harris T, Lohsoonthorn V, et al. Risk of preterm delivery in relation to vaginal bleeding in early pregnancy. Eur J Obstet Gynecol Reprod Biol. 2007; 135(2): 158-63. doi: 10.1016/j.ejogrb.2006.12.003

21. Sapra KJ, Joseph KS, Galea S, et al.Signs and Symptoms of Early Pregnancy Loss. Reprod Sci. 2017; 24(4): 502-513. doi: 10.1177/1933719116654994

22. Lykke JA, Dideriksen KL, Lidegaard $\varnothing$, et al. First-trimester vaginal bleeding and complications later in pregnancy. Obstet Gynecol. 2010; 115(5): 935-944. doi: 10.1097/AOG.0b013e3181da8d38
23. Magnus MC, Wilcox AJ, Morken NH, et al. Role of maternal age and pregnancy history in risk of miscarriage: prospective register based study. BMJ. 2019; 364: 1869. doi: 10.1136/bmj.1869

24. Ghimire PR, Akombi-Inyang BJ, Tannous C, et al. Association between obesity and miscarriage among women of reproductive age in Nepal. PLoS One. 2020; 15(8): e0236435. doi: 10.1371/journal.pone.0236435

25. du Fossé NA, van der Hoorn MP, van Lith JMM, et al. Advanced paternal age is associated with an increased risk of spontaneous miscarriage: a systematic review and meta-analysis. Hum Reprod Update. 2020; 26(5): 650-669. doi: 10.1093/humupd/dmaa010

26. San Lazaro Campillo I, Meaney S, Sheehan J, et al. University students' awareness of causes and risk factors of miscarriage: a cross-sectional study. BMC Womens Health. 2018; 18(1): 188. doi: 10.1186/s12905018-0682-1

27. Feodor Nilsson S, Andersen PK, Strandberg-Larsen K, et al. Risk factors for miscarriage from a prevention perspective: a nationwide follow-up study. BJOG. 2014; 121(11): 1375-84. doi: 10.1111/1471-0528.12694

28. Singh S, Doyle P, Campbell OMR, et al. Pregnant women who requested a '108' ambulance in two states of India. BMJ Glob Health. 2018; 3(3): e000704. doi: 10.1136/bmjgh-2017-000704

29. Bills CB, Newberry JA, Darmstadt G, et al. Reducing early infant mortality in India: results of a prospective cohort of pregnant women using emergency medical services. BMJ Open. 2018; 8(4): e019937. doi: 10.1136/bmjopen-2017-019937

30. Singh S, Doyle P, Campbell OM, et al. Interfacility transfer of pregnant women using publicly funded emergency call centre-based ambulance services: a cross-sectional analysis of service logs from five states in India. BMJ Open. 2017; 7(6): e015077. doi: 10.1136/bmjopen-2016-015077

31. Strehlow MC, Newberry JA, Bills CB, et al. Characteristics and outcomes of women using emergency medical services for third-trimester pregnancy-related problems in India: a prospective observational study. BMJ Open. 2016; 6(7): e011459. doi: 10.1136/bmjopen-2016-011459

32. Cantwell K, Burgess S, Morgans A, et al. Temporal trends in falls cases seen by EMS in Melbourne: The effect of residence on time of day and day of week patterns. Injury. 2016; 47(1): 266-71. doi: 10.1016/j. injury.2015.10.073

33. Faramand Z, Frisch SO, Martin-Gill C, et al. Diurnal, weekly and seasonal variations of chest pain in patients transported by emergency medical services. Emerg Med J. 2019; 36(10): 601-607. doi: 10.1136/ emermed-2019-208529

34. Ramgopal S, Dunnick J, Owusu-Ansah S, et al. Weather and Temporal Factors Associated with Use of Emergency Medical Services. Prehosp Emerg Care. 2019; 23(6): 802-810. doi: 10.1080/10903127.2019.1593563

35. Javaudin F, Hamel V, Legrand A, et al. Unplanned out-of-hospital birth and risk factors of adverse perinatal outcome: findings from a prospective cohort. Scand J Trauma Resusc Emerg Med. 2019; 27(1): 26. doi: 10.1186/s13049-019-0600-z

36. Rzońca P, Gałązkowski R, Wójcik-Fatla A, et al. Missions of the Helicopter Emergency Medical Service in rural and urban areas in Poland - A comparative retrospective analysis. Ann Agric Environ Med. 2019; 26(2): 355-360. doi:10.26444/aaem/106223

37. Rzońca P, Świeżewski SP, Jalali R, et al. Helicopter Emergency Medical Service (HEMS) Response in Rural Areas in Poland: Retrospective Study. Int J Environ Res Public Health. 2019; 16(9): 1532. doi: 10.3390/ ijerph16091532

38. Dechert TA, Sarani B, McMaster M, et al. Medical emergency team response for the non-hospitalized patient. Resuscitation. 2013; 84(3): 276-9. doi: 10.1016/j.resuscitation.2012.06.022 